\title{
VITAMIN D DEFICIENCY IN PATIENTS WITH PSORIASIS AND PSORIATIC ARTHRITIS
}

\author{
JINAN Q MOHAMMED ${ }^{1 *}$, ABDULSATAR J MATHKHOR², AMER S KHUDHAIRY ${ }^{3}$
}

${ }^{1}$ Dermatology Unit in Basrah Teaching Hospital Basrah, Iraq. ${ }^{2}$ Rheumatology Unit in Basrah Teaching Hospital Basrah, Iraq ${ }^{3}$ Rheumatology Unit in Alfayhaa Teaching Hospital Basrah, Iraq. Email: jinanbubsari@yahoo.com

Received: 06 September 2020, Revised and Accepted: 06 October 2020

ABSTRACT

Objective: The objective of this study is to investigate the association between Vitamin D level and psoriasis, in particular in our city of the long, hot, and sunny weather, in an attempt to add a clarification to this controversial subject.

Methods: A case-control study included 120 patients with psoriasis and 38 patients with psoriatic arthritis (PsA); 89 (56.3\%) patients were male. Psoriasis area and severity index (PASI) was calculated for all patients with psoriasis and disease activity score using 28 joints (DAS28) and erythrocyte sedimentation rate (DAS28) was measured for all patients with PsA. The control group comprised 164 age- and sex-matched participants (91 males and 73 females). Vitamin D serum level was performed for both patients and controls.

Results: Vitamin D levels in both patients and controls were $17.4 \pm 7.7$ and $28.3 \pm 5.6$, respectively. The level of Vitamin D was lower in a patient with disease duration equal and more than 10 years than those with a disease duration < 10 years. There is no significant difference in Vitamin D levels between the two patient subgroups. Lower Vitamin D levels were associated with high PASI and high DAS28 in psoriasis and PsA, respectively.

Conclusion: Patients with psoriasis and PsA associated with low levels of serum Vitamin D. Vitamin D deficiency was found to be associated with long disease duration in both psoriasis and PsA. Patients with active disease have lower Vitamin D levels.

Keywords: Vitamin D, Psoriasis, Psoriatic arthritis, Psoriatic area, Disease severity index.

(C) 2020 The Authors. Published by Innovare Academic Sciences Pvt Ltd. This is an open access article under the CC BY license (http://creativecommons. org/licenses/by/4. 0/) DOI: http://dx.doi.org/10.22159/ajpcr.2020.v13i11.39653

\section{INTRODUCTION}

Psoriasis is defined as a chronic, non-contagious, multisystem inflammatory autoimmune skin disorder that presents with an erythematous scaly rash on the extensor surfaces and trunk, it also affects the scalp, palms, and soles [1]. It may affect the nails in a frequency of $50-79 \%$ of patients with skin psoriasis and up to $80 \%$ of patients with psoriatic arthritis (PsA) [2]. Psoriasis appears to be influenced by genetic and immune-mediated pathological mechanisms. The pathogenesis of psoriasis is still not completely understood, but psoriasis is associated with excessive T-cell activity, as well as keratinocyte differentiation $[3,4]$, and different pro-inflammatory mediators such as tumor necrosis factor- $\alpha$, interleukin (IL)-17, and IL-23 [5]. The worldwide prevalence is approximately $1-3 \%$ [6]. PsA which is inflammatory arthritis develops in $30 \%$ of patients with psoriasis and presents with pain and stiffness in the affected joints. Psoriasis and PsA affect women and men in a ratio of 1:1 [7]. PsA has heterogeneous presentations and may involve both the axial skeleton (spondylitis and/or sacroiliitis) and the peripheral joints. It also affects skin, nails, and entheses [7]. Different comorbidities may be associated with psoriasis such as diabetes mellitus, hypertension, and obesity. Recent studies showed an association between psoriasis and low bone mineral density [6]. Vitamin D is the oldest hormone and the sun ultraviolet B its main source. It is a major regulator of mineral ion homeostasis. Its deficiency is known to cause rickets, osteomalacia, and osteoporosis. Vitamin D has various biological processes through its active form, calcitriol, or $1 \alpha, 25$-dihydroxyvitamin $\mathrm{D}[1 \alpha, 25(\mathrm{OH}) 2 \mathrm{D}]$. Low levels of 25-hydroxyvitamin D [25(OH)D], the principal circulating form of Vitamin D, are present in one-third to $50 \%$ of otherwise healthy middle aged to elderly adults. Impaired synthesis due to inadequate sun exposure or dark skin and inadequate dietary intake are the principal causes of low 25(OH)D levels [8], it is known that the physiological actions of Vitamin D are very broad. Vitamin D receptors and CYP271B (enzyme responsible for 25-hydroxyvitamin D synthesis have been identified in different cell types such as the enterocytes, osteoblasts, immune cells, parathyroid cells, keratinocytes, and ovarian cells [9]. Evidence suggests that Vitamin D plays a crucial role in modulating the function of dendritic cells and regulating keratinocytes and T-cell proliferation [10]. The association of several dermatological conditions, such as atopic dermatitis and psoriasis, with low or deficient Vitamin D blood levels, has been addressed in literature [11-13]. There are many debates on the definition of Vitamin D deficiency. However, there is an agreement that serum Vitamin D level below $20 \mathrm{ng} / \mathrm{mL}$ is an indication of Vitamin D deficiency; whereas Vitamin D insufficiency is defined as a serum level ranging from 20 to $30 \mathrm{ng} / \mathrm{Ml}$ [14]. In this study, we investigated the association between psoriasis and the level of Vitamin D, in an attempt to add another clarification to the current controversy in the available data [15], in particular in our sunny, hot, and long summer city.

\section{METHODS}

This was a case-control study carried out in the outpatient departments of Dermatology and Rheumatology in Basra Teaching Hospital from January 2019 to February 2020. A sample of 158 (89 males and 69 females) patients was divided into two subgroups, 120 patients with psoriasis, diagnosed by a dermatologist in the dermatology outpatient, and 38 patients with PsA, who fulfilled the classification criteria of PsA [16], and 164 (91 males and 73 females), age- and sex-matched controls recruited from the general population were enrolled for this study. Data collection was done through an interview with the patients using a special questionnaire developed by the researchers. The questionnaire included information regarding age, sex, disease duration, and drug history. All patients were examined and investigated for complete blood cell count and erythrocyte sedimentation rate (ESR). Vitamin D serum levels were measured for both the patient group and controls. Psoriasis area and severity index (PASI) [17] was calculated by the dermatologist for all patients with psoriasis, the PASI is a measure of the average redness, thickness, and scaliness of the lesions (each graded on a 0-4 scale), weighted according to the area 
Table 1: Demographic distribution of both patient group and controls

\begin{tabular}{llll}
\hline Characteristics & Patient group & Control group & p-value \\
\hline Total no. (\%) & $158(100 \%)$ & $164(100 \%)$ & \\
Psoriasis & $120(75.9 \%)$ & & \\
Psoriatic arthritis & $38(24.1 \%)$ & $91(55.5 \%)$ & $>0.05$ \\
Males & $89(56.3 \%)$ & $73(44.5 \%)$ & $>0.05$ \\
Females & $69(43.6 \%)$ & $53.1 \pm 9.8$ & \\
Age (mean) & $51.4 \pm 7.8$ & & \\
Disease duration (mean) & $14.1 \pm 5.3$ & & \\
Treatment & Topical, methotrexate, anti-tumor necrosis factor & & \\
\hline
\end{tabular}

Table 2: Vitamin D level is lower in the patients' group than that of controls

\begin{tabular}{llll}
\hline Characteristic & Patient group & Controls & p-value \\
\hline Vitamin D level (mean) & $17.4 \pm 7.7 \mathrm{ng} / \mathrm{ml}$ & $28.3 \pm 5.6 \mathrm{ng} / \mathrm{ml}$ & $<0.05$ \\
\hline
\end{tabular}

Table 3: Vitamin $D$ level is lower in patients with disease duration equal and more than 10 years

\begin{tabular}{llll}
\hline Disease duration & $<10$ years & $\begin{array}{l}\text { 10 years } \\
\text { and more }\end{array}$ & p-value \\
\hline Vitamin D level (mean) & $24.8 \pm 4.8 \mathrm{ng} / \mathrm{ml}$ & $\begin{array}{l}14.4 \pm 6.5 \\
\mathrm{ng} / \mathrm{ml}\end{array}$ & $<0.05$ \\
& & & \\
\hline
\end{tabular}

Table 4: Vitamin D level in patients with psoriasis slightly higher than that in psoriatic arthritis

\begin{tabular}{llll}
\hline Characteristic & Psoriasis & Psoriatic arthritis & p-value \\
\hline $\begin{array}{l}\text { Vitamin D level } \\
\text { (mean) }\end{array}$ & $17.8 \pm 7.8 \mathrm{ng} / \mathrm{ml}$ & $15.9 \pm 7.2 \mathrm{ng} / \mathrm{ml}$ & $>0.05$ \\
\hline
\end{tabular}

Table 5: Vitamin D level is lower in psoriasis with high PASI compared to psoriasis with low-moderate PASI and is lower in psoriatic arthritis with high disease activity score using 28 joints compared to psoriatic arthritis with low-moderate disease activity score using 28 joints

\begin{tabular}{lll}
\hline Characteristics & Vitamin D level & p-value \\
\hline Psoriasis with high PASI & $10.9 \pm 1.9 \mathrm{ng} / \mathrm{ml}$ & $<0.05$ \\
Psoriasis with low-moderate PASI & $25.2 \pm 3.9 \mathrm{ng} / \mathrm{ml}$ & \\
Psoriatic arthritis with high disease & $11.4 \pm 2.1 \mathrm{ng} / \mathrm{ml}$ & $<0.05$ \\
activity score using 28 joints & & \\
Psoriatic arthritis with low-moderate & $25.8 \pm 3.2 \mathrm{ng} / \mathrm{ml}$ & \\
disease activity score using 28 joints & & \\
\hline
\end{tabular}

PASI: Psoriasis area and severity index

of involvement (head, upper extremities, trunk, and lower extremities). Disease activity score using 28 joints (DAS28) and ESR [18] were measured for all patients with PsA by a rheumatologist. Elderly patients, postmenopausal women, patients with endocrine, metabolic, renal, malabsorption diseases, and patients using systemic steroids were excluded from the study.

\section{Ethical consideration}

Verbal consent was obtained from all participants before their involvement. The study was conducted in accordance with the principles of the Declaration of Helsinki.

Statistical analysis

SPSS software version 25.0 was used for data analysis. Percentages and mean were used to present the data in tables. A comparison of study groups was carried out using the Chi-square test for categorical data and Student's t-test for continuous data. $\mathrm{p}<0.05$ was considered statistically significant.

\section{RESULTS}

The demographic distributions of patients and controls are shown in Table 1. From the total sample of 158 patients (120 with psoriasis and 38 with PsA), 89 (56.3\%) patients were male and 69 (43.6\%) were female, with mean age and disease duration were $51.4 \pm 7.8$ and $14.1 \pm 5.3$, respectively. There were 164 (91 males and 73 females) in the control group. Table 2 shows Vitamin D levels in both patients and controls which were $17.4 \pm 7.7 \mathrm{ng} / \mathrm{ml}$ and $28.3 \pm 5.6 \mathrm{ng} / \mathrm{ml}$, respectively, the difference was statistically significant $(\mathrm{p}<0.05)$. Table 3 shows the level of Vitamin D in relation to disease duration, which was $24.8 \pm 4.8 \mathrm{ng} / \mathrm{ml}$ in patients with disease duration $<10$ years, and was $14.4 \pm 6.5 \mathrm{ng} / \mathrm{ml}$ in patients with disease duration equal and more than 10 years, the difference was statistically significant $(p<0.05)$. Vitamin $D$ level was $17.8 \pm 7.8 \mathrm{ng} / \mathrm{ml}$ in patients with psoriasis which is slightly higher than that of patients with PsA, but the difference is statistically not significant ( $>0.05$ ), as shown in Table 4. Table 5 shows the relationship between the level of Vitamin D and the disease activity in both patient subgroups, psoriasis, and PsA. Lower Vitamin D levels were associated with high PASI and high DAS28 in both psoriasis and PsA, respectively.

\section{DISCUSSION}

Vitamin D has different functions in the skin, it inhibits the proliferation and induces the differentiation of keratinocytes, modulates the immune system response. These actions occur by the binding of Vitamin D in their receptors present in keratinocytes that capable of producing Vitamin D which acts on receptors in an autocrine action. The important role of Vitamin D in psoriasis can be demonstrated by the therapeutic response to Vitamin D analogs used topically in the treatment of this disease. Vitamin D inhibits important cytokines for Th1 and Th17 differentiation which are important cytokines in the pathogenesis of psoriasis $[9,19,20]$. Therefore, low vitamin D level implicated in the pathogenesis of this disease. In this study, we found a low level of Vitamin D in patients with psoriasis compared to the healthy controls, a result comparable to a study done by Gisondi et al. [21] who compared 145 patients with psoriasis to 112 patients with rheumatoid arthritis (RA) and 141 healthy controls and was found significantly lower serum levels of Vitamin D in both the RA and psoriatic patients than in the controls, but no significant difference in Vitamin D level between RA and psoriasis groups, and psoriasis patients presented with 2.5 times greater risk of Vitamin D deficiency than the controls. Orgaz-Molina et al. [22] demonstrated significantly lower Vitamin D levels in psoriatic patients when compared to healthy controls, which is in agreement with our study findings. Our study findings were also comparable to studies conducted by Chandrashekar et al., Myśliwiec et al., and Mattozzi et al. [23-25] who all demonstrated that patients with psoriasis presented lower values of Vitamin D compared to healthy controls. In this study, we were demonstrated lower Vitamin D level in PsA patients compared to that in controls, result is comparable to the findings of studies done by Ibrahim et al. and Touma et al. [26,27] who demonstrated lower Vitamin D levels compared to healthy controls in their study populations. The lower Vitamin D level in our study group 
than that in the general population may be attributed to several factors. Low Vitamin D levels can either represent the etiological factor or it may result as a consequence of psoriasis and PsA, it may result from the lack of sun exposure, which may be related to the use of women veil, the use of drugs that interfere with Vitamin D metabolism such as steroids or immunosuppressive medications, and from low dietary Vitamin D intake $[4,28]$. In this study, a low level of Vitamin D was found to be associated with long disease duration, the result is comparable to the findings of studies done by Filoni et al. [4] and Beata and Ligia [13]. In addition to the attitude of using the veils by women in our society, there is a fact that patients with psoriasis always keep their affected areas covered. This attitude, with prolonged disease duration, will result in decreased UV exposure and as a consequence, decreased Vitamin D levels. Therefore, patients with a long duration possibly could be more prone to Vitamin D reduced serum levels $[4,13]$. In contrast, lower Vitamin D levels may be implicated in the etiology of psoriasis. Since psoriasis is considered to be a Th1-Th17-dependent autoimmune inflammatory disease that involves both innate and acquired immunity, and low Vitamin D level is known to be associated with an increased risk of developing Th1-mediated autoimmune diseases [29]. In this study, we found that lower Vitamin D levels were associated with high disease activity in both subgroups of our study population. Regarding psoriasis, our study finding is comparable to the findings of Chandrashekar et al. and Mattozzi et al. $[23,25]$ who demonstrated that serum 25-hydroxyvitamin D showed a significant negative correlation with the PASI score. However, of note, the correlation between psoriasis severity and Vitamin D levels is still controversial [4], and further studies are needed to clarify this relationship. Furthermore, we found that lower Vitamin D level was associated with high disease activity (DAS28) in PsA patients, which is comparable with the finding of a study conducted by Ibrahim et al. [26], who documented that PsA patients presented an inverse correlation between Vitamin D levels and disease activity. In general, our study findings support studies that demonstrated an inverse relationship between Vitamin D level and both psoriasis and PsA.

\section{CONCLUSION}

Patients with psoriasis and PsA associated with low levels of serum Vitamin D. Vitamin D deficiency was found to be associated with long disease duration in both psoriasis and PsA. Patients with active disease have lower Vitamin D levels.

\section{ACKNOWLEDGMENT}

We kindly appreciate the role of all participants in the study.

\section{AUTHORS' CONTRIBUTIONS}

JM made a significant contribution to the acquisition of data, analysis, and drafting of the manuscript. AM has made a substantial contribution to the conception and design, interpretation of data. AK participated in the design of the experiment.

\section{CONFLICTS OF INTEREST}

The authors declare that they have no conflicts of interest.

\section{AUTHORS' FUNDING}

No funding was received for this manuscript.

\section{REFERENCES}

1. Rasmussen GS, Maindal HT, Lomborg K. Self-management in daily life with psoriasis: An integrative review of patient needs for structured education. Nurs Res Pract 2012;2012:1-19.

2. Bardazzi F, Starace M, Bruni F, Magnano M, Piraccini BM, Alessandrini A. Nail psoriasis: An updated review and expert opinion on available treatments, including biologics. Acta Derm Venereol 2019;99:516-23.
3. Allayali A, Niaz G, Al Hawsawi K, Fatani M, Siddiqui I, Baghdadi R, et al. Association between Vitamin D deficiency and psoriasis: A casecontrol study. J Clin Exp Dermatol Res 2018;9:1000442.

4. Filoni A, Vestita M, Congedo M, Giudice G, Tafuri S, Bonamonte D. Association between psoriasis and Vitamin D: Duration of disease correlates with decreased Vitamin D serum levels: An observational case-control study. Medicine (Baltimore) 2018;97:10-3

5. Keaney TC, Kirsner RS. New insights into the mechanism of narrowband UVB therapy for psoriasis. J Invest Dermatol 2010;130:2534.

6. Dos M, Diniz S, Pinto JM, Marta M, Soares S. Serum levels of 25oh Vitamin D in psoriatic patients and control subjects. JOJ Dermatol Cosmet 2019;1:65-8.

7. Sankowski AJ, Łebkowska UM, Ćwikła J, Walecka I, Walecki J. Psoriatic arthritis. Polish J Radiol 2013;78:7-17.

8. Hallak A, Malhis M, Abajy MY. Vitamin-D deficiency and risk of acute coronary syndrome. Int J Pharm Pharm Sci 2018;10:171.

9. Soleymani T, Hung T, Soung J. The role of Vitamin D in psoriasis: A review. Int J Dermatol 2015;54:383-92.

10. Rendon A, Schäkel K. Psoriasis pathogenesis and treatment. Int J Mol Sci 2019;20:1-28.

11. Vestita M, Filoni A, Congedo M, Foti C, Bonamonte D. Vitamin D and atopic dermatitis in childhood. J Immunol Res 2015;2015:257879.

12. Solak B, Dikicier BS, Celik HD, Erdem T. Bone mineral density, 25-OH Vitamin D and inflammation in patients with psoriasis. Photodermatol Photoimmunol Photomed 2016;32:153-60.

13. Beata BC, Ligia BW. Serum Vitamin D level-the effect on the clinical course of psoriasis. Postep Dermatol Alergol 2016;33:445-9.

14. García de Tena J, Abejón L, Horcajo P. Vitamin D insufficiency. N Engl J Med 2011;364:248-54

15. Kamangar F, Koo J, Heller M, Lee E, Bhutani T. Oral Vitamin D, still a viable treatment option for psoriasis. J Dermatol Treat 2013;24:261-7.

16. Taylor W, Gladman D, Helliwell P, Marchesoni A, Mease P, Mielants H. Classification criteria for psoriatic arthritis: Development of new criteria from a large international study. Arthritis Rheum 2006;54:2665-73.

17. Feldman SR, Krueger GG. Psoriasis assessment tools in clinical trials. Ann Rheum Dis 2005;64:65-8.

18. Salaffi F, Ciapetti A, Carotti M, Gasparini S, Gutierrez M. Disease activity in psoriatic arthritis: Comparison of the discriminative capacity and construct validity of six composite indices in a real world. Biomed Res Int 2014;2014:528105

19. Mattozzi C, Paolino G, Richetta AG, Calvieri S. Psoriasis, Vitamin D and the importance of the cutaneous barrier's integrity: An update. J Dermatol 2016;43:507-14

20. Mostafa WZ, Hegazy RA. Vitamin D and the skin: Focus on a complex relationship: A review. J Adv Res 2013;6:793-804.

21. Gisondi P, Rossini M, Di Cesare A, Idolazzi L, Farina S, Beltrami G, et al. Vitamin D status in patients with chronic plaque psoriasis. $\mathrm{Br} \mathrm{J}$ Dermatol 2012;166:505-10.

22. Orgaz-Molina J, Buendía-Eisman A, Arrabal-Polo MA, Ruiz JC, Arias-Santiago S. Deficiency of serum concentration of 25-hydroxyvitamin D in psoriatic patients: A case-control study. J Am Acad Dermatol 2012;67:931-8.

23. Chandrashekar L, Kumari GR, Rajappa M, Revathy G, Munisamy M, Thappa DM. 25-hydroxy Vitamin D and ischaemia-modified albumin levels in psoriasis and their association with disease severity. $\mathrm{Br} \mathrm{J}$ Biomed Sci 2015;72:56-60.

24. Myśliwiec H, Kiluk P, Żelazowska-Rutkowska B, Baran A, Milewska AJ, Myśliwiec P, et al. Vitamin D deficiency in psoriatic patients in North-East of Poland. Przegl Lek 2016;73:610-4

25. Mattozzi C, Paolino G, Salvi M, Macaluso L, Scarnò M, De Vita G, et al. Correlation between plasmatic levels of Vitamin D and PASI score. G Ital Dermatol Venereol 2018;153:155-60.

26. Ibrahim A, Ltamimy H, Rayan M, Abdul-Hamied H. Measurement of Vitamin D and Its relation to psoriatic arthritis. Al Azhar Assiut Med J 2013;11:292-304.

27. Touma Z, Eder L, Zisman D, Feld J, Chandran V, Rosen CF, et al. Seasonal variation in Vitamin D levels in psoriatic arthritis patients from different latitudes and its association with clinical outcomes. Arthritis Care Res 2011;63:1440-7.

28. Bertrand KA, Giovannucci E, Liu Y, Malspeis S, Eliassen AH, Wu K, et al. Determinants of plasma 25-hydroxyvitamin D and development of prediction models in three US cohorts. Br J Nutr 2012;108:1889-96.

29. Cai Y, Fleming C, Yan J. New insights of T cells in the pathogenesis of psoriasis. Cell Mol Immunol 2012;9:302-9. 